\title{
El sobreendeudamiento como problema legal y social. Propuesta de reforma del Código de Protección y Defensa del Consumidor
}

\section{Over-indebtedness as a legal and social problem. Proposal for the reform of the Consumer Protection and Defense Code}

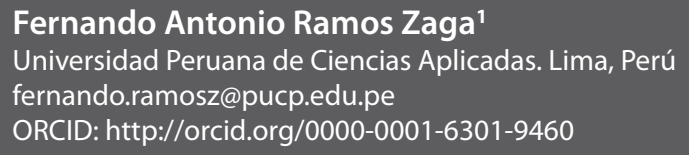

Citar como: Ramos, F. (2021). El sobreendeudamiento como problema legal y social. Propuesta de reforma del Código de Protección y Defensa del Consumidor. Desde el Sur, 13(1), e0011

\section{RESUMEN}

Este trabajo aborda el sobreendeudamiento como fenómeno de suma importancia cuyos efectos en la vida de las personas afectadas y a nivel social son sumamente negativos, por lo que el asunto merece ser regulado por el Estado. Se busca conceptualizar el sobreendeudamiento como aquella situación que sitúa al consumidor en una situación económica desfavorable debido a la cantidad de sus deudas y a su falta de liquidez, hasta el punto de comprometer el sustento propio y el de su familia. El sobreendeudamiento tiene consecuencias sociales negativas, causa daños al deudor y también a la sociedad. Ante la ausencia de protección específica para el consumidor sobreendeudado, se plantea una sugerencia de modificación al Código de Protección al consumidor teniendo en cuenta la experiencia de otros países.

\section{PALABRAS CLAVE}

Sobreendeudamiento, publicidad financiera, créditos 


\section{ABSTRACT}

This research addresses over-indebtedness as a phenomenon of enormous significance, whose effects on the lives of the people affected and on society as a whole are extremely negative, indicating that the issue merits regulation by the State. It seeks to conceptualize over-indebtedness as a situation that places the consumer in an unfavorable economic position, as a result of the amount of their debt and their lack of liquidity, to the point of compromising their own maintenance and that of their family. Over-indebtedness has negative social consequences, causing damage to both the debtor and to society. In the absence of specific protection for consumers to address indebtedness, a suggestion is made for modification of the Consumer Protection Code, taking into account the experience of other countries.

\section{KEYWORDS}

over-indebtedness, financial advertising, credits

\section{Introducción}

El crédito es un mecanismo indispensable en la adquisición de bienes y servicios esenciales para la vida, además de permitir la adquisición de bienes de consumo.

En el Perú la oferta de crédito se hizo más accesible con la aparición de las microfinancieras en la década de 1980. En ese contexto el crédito comenzó a formar parte del presupuesto familiar como un mecanismo de inversión en los emprendimientos familiares.

Una de las causas que favorecen el sobreendeudamiento implica otorgar créditos sin observar las condiciones crediticias, como la capacidad de pago y endeudamiento en otras instituciones financieras.

Por lo tanto, incluso si los requisitos formales para la validez del contrato de crédito están presentes, el incumplimiento de los supuestos antes mencionados rompe con el principio de buena fe por parte de la entidad financiera, dado que no ha tomado las precauciones necesarias para garantizar el pago de la deuda del crédito otorgado.

Además de los problemas derivados de la escasa educación financiera y la constante publicidad, no se puede ignorar situaciones imprevistas para el usuario de servicios financieros, como es el caso de quienes inesperadamente pierden su trabajo, sin poder saldar sus deudas, lo que los lleva a formar parte de la lista de personas sobreendeudadas. 
Es un hecho que las sociedades tienden a vivir en una cultura de endeudamiento, que se ve agravada por el otorgamiento excesivo de créditos. En el caso del Perú, tales tácticas desencadenan el sobreendeudamiento, lo que genera serios problemas sociales y, por lo tanto, merecen ser analizadas en el ámbito legal.

Cabe señalar que el sobreendeudamiento es una condición en la que se encuentra el consumidor individual, ante la falta de recursos financieros suficientes para pagar sus deudas sin perjuicio de su propia subsistencia o la de su familia.

De acuerdo con Esteban, Zegarra y Acosta (2016), tenemos el sobreendeudamiento activo, causado por un hecho por parte del consumidor, que puede ser consciente o inconsciente, y el sobreendeudamiento pasivo, que surge de circunstancias más allá de su control, como en el caso de desempleo repentino.

El fenómeno de sobreendeudamiento ha recibido atención especial en varios países. En el Perú observamos que esta atención no fue prestada por el legislador, a pesar de que es un tema de debate constante.

Es necesario considerar las diversas medidas de prevención y mecanismos de solución para el fenómeno, teniendo en cuenta las medidas adoptadas a través del derecho comparado, que en muchos aspectos puede servir como inspiración jurídica para el caso peruano.

Es pertinente mencionar que el sobreendeudamiento del presente trabajo considera solo la situación de las personas naturales, considerando que en el caso del endeudamiento de personas jurídicas existe un procedimiento concursal regulada por la Ley General del Sistema Concursal.

Entre las consecuencias sociales negativas, debe destacarse la violación de la dignidad de la persona humana en vista del resultado del sobreendeudamiento, que a veces pone al consumidor en la condición de mal pagador con la calificación crediticia negativa en centrales de riesgo, así como la reducción de las posibilidades de este individuo de acceder al mercado laboral.

Además de esta consecuencia directa, no se pueden olvidar muchas otras consecuencias vinculadas indirectamente, como la estabilidad familiar, además de considerar el hecho de que el crédito es el único mecanismo posible que permite generar oportunidades de negocio para el consumidor financiero y su familia.

A través del presente trabajo, se pretende visibilizar la vulnerabilidad del consumidor frente a los mecanismos de otorgamiento de crédito dentro del sistema financiero, ante la ausencia de un mecanismo legal 
específico que prevenga y regule el sobreendeudamiento, como ha estado ocurriendo en otros sistemas legales.

Es de suma importancia resaltar la relevancia del presente trabajo, pues pretende demostrar la necesidad de crear un mecanismo para la prevención del sobreendeudamiento a través de la modificación del Código de Protección al Consumidor.

\section{Sobreendeudamiento}

\section{Concepto de sobreendeudamiento}

El sobreendeudamiento puede ser el resultado de varios factores, desde casos fortuitos hasta el consumo desenfrenado. Por lo tanto, es posible decir que el fenómeno se caracteriza por la insuficiencia de los recursos económicos del individuo para cumplir con sus obligaciones financieras, cuyo resultado se traduce en un aumento de sus deudas respecto a su nivel de ingresos.

De acuerdo con Esteban, Zegarra y Acosta (2018), el endeudamiento es la condición financiera de los deudores bajo la cual su endeudamiento es excesivo en términos de sus ingresos y su capacidad de pago, lo cual lo pone en riesgo de afectar su calidad de vida y la de sus familias.

El sobreendeudamiento puede ser definido como la imposibilidad del deudor para pagar sus deudas excluyendo las deudas tributarias, tras pasar por una dificultad que afecte su capacidad de ingresos.

El sobreendeudamiento también afecta considerablemente al consumidor de buena fe, cuyo propósito inicial era pagar sus deudas, pero dejó de hacerlo por una razón imprevista y ajena a su voluntad.

El sobreendeudamiento, también conocido como insolvencia, se refiere a situaciones en las que la deuda se hace imposible de manera indefinida, e incluso existe una amenaza grave para su subsistencia en caso de pagar su deuda.

González y González-Vega (2003) señalan que el endeudamiento se caracteriza por aquellas circunstancias en las que el resultado final del contrato de crédito no es el esperado. Los autores contemplan tres situaciones que pueden configurarse como sobreendeudamiento. La primera ocurre cuando el cliente no está dispuesto a pagar, independientemente de su capacidad de pago. En este caso existe un incumplimiento total del contrato. La segunda ocurre cuando el cliente tiene que realizar acciones en desmedro de su economía a fin de cumplir con sus obligaciones financieras. La última situación ocurre cuando el cliente está dispuesto a pagar el préstamo, pero no tiene la capacidad de pago para hacerlo y ocurre un incumplimiento parcial o total. 
Por lo tanto, es posible concluir que el sobreendeudamiento es una deuda superior a la que puede ser soportada por los ingresos del individuo. La situación de sobreendeudamiento de los consumidores de buena fe constituye un fenómeno jurídico-social y, por lo tanto, necesita alguna solución, tal como ocurre en los casos previstos para las personas jurídicas en la Ley General del Sistema Concursal, que plantea soluciones para la liquidación o pago de las deudas frente a los acreedores.

\section{Sobreendeudamiento activo y pasivo}

Diversos autores clasifican el sobreendeudamiento en activo y pasivo (Vásquez Vílchez, 2017; Holguín Chambilla, 2018; Astorne Guillén, Aquije Milanta y Paredes Núñez Melgar, 2017; Rengifo Vásquez y Ampuero OvaIle, 2018; Japaze, 2015). El sobreendeudamiento activo es el resultado de una acumulación desmesurada de deudas (Astorne Guillén, Aquije Milanta y Paredes Núñez Melgar, 2017). De otro lado, el sobreendeudamiento pasivo es el causado por un evento imprevisto, es decir, la deuda derivada del desempleo, la enfermedad que afecta a algún miembro de la familia, el divorcio, entre otros (Rengifo Vásquez y Ampuero Ovalle, 2018).

Se puede decir, entonces, que el sobreendeudamiento activo es causado por el consumidor, mientras que el sobreendeudamiento pasivo surge de circunstancias más allá de su control.

Según Japaze (2015), el sobreendeudamiento activo distingue dos tipos de deudores. El primer grupo comprende a quienes adquieren deudas conscientes de que no podrán pagarlas, es decir, practican un acto de mala fe, sabiendo que el acreedor no podrá cobrar la deuda. En el segundo grupo se describe a los consumidores que están sobreendeudados debido a la falta de planificación en sus gastos sin ningún elemento de mala fe, porque cuando asumen sus deudas tienen la voluntad de pagarlas, pero, debido a la falta de control sobre sus gastos e ingresos, asumen más compromisos financieros de los que sus ingresos son capaces de soportar. Esto ocurre porque el deudor sobreestima sus ingresos a causa de la incapacidad de administrar sus gastos o ceder ante las tentaciones del consumo y la publicidad.

El principal problema que implica el sobreendeudamiento activo es precisamente la dificultad para diferenciarlos, ya que el punto controversial es la existencia o ausencia de buena fe y, por lo tanto, requiere un análisis detallado y subjetivo de cada caso. 


\section{Deudor de buena fe}

De hecho, la noción de buena fe en asuntos de sobreendeudamiento implica que el elemento intencional que evidencia el conocimiento del consumidor respecto a su voluntad de pagar todas sus deudas.

La buena fe del consumidor se observa en su determinación a pagar sus deudas, de acuerdo con su condición económica. Esto no quiere decir que la existencia de muchas deudas caracterice la buena fe del consumidor, sobre todo porque este hecho es precisamente lo que caracteriza su condición de sobreendeudamiento.

Sin embargo, Neme Villarreal (2009) menciona respecto a las obligaciones contractuales que no es suficiente la suposición del deudor de que cumple suficientemente el interés de su contraparte, desconociendo el requisito objetivo de buena fe que exige una conducta efectiva. En línea con lo antes mencionado, Caballero Germain (2018) menciona que el deudor honesto debe cumplir con un requerimiento general de buena fe y contar con ciertas conductas que demuestren la correcta actuación del deudor como, por ejemplo, la no omisión de activos o créditos.

\section{Proveedor de crédito de buena fe}

En el caso de las relaciones con los consumidores, a menudo se observan conductas abusivas, que pueden ocurrir a través de actos que apuntan directamente a causar daño al consumidor, o incluso sin la intención del daño, pero cuyas consecuencias van en detrimento del consumidor (De la Maza Gazmuri, 2007; Villanueva, 2010; Rodríguez, 2016; Herrera Pachari, 2015; Gallardo Mantilla y Minchan Huamán, 2017).

En relación con los contratos de crédito, el abuso de derechos puede existir cuando la entidad financiera no cumple con los aspectos esenciales para el otorgamiento del crédito, como la capacidad de pago por parte del consumidor, incluso cuando se cumplen los requisitos formales de validez del contrato, ya que corresponde al proveedor imponer condiciones para el otorgamiento del crédito.

El financiamiento otorgado de manera imprudente, sin contemplar por parte de la entidad financiera la capacidad crediticia real de quien solicita el crédito, prácticamente induce al consumidor al incumplimiento.

Por lo tanto, la falta de diligencia del funcionario o analista de crédito al otorgar el crédito, respecto a la capacidad de pago del prestatario, no es considerada como un acto de buena fe por parte de la entidad financiera. 


\section{Crédito y consumo}

La oferta de crédito al consumo se originó en Estados Unidos, luego se expandió a Europa y años después a los países económicamente menos favorecidos.

En el Perú el crédito de consumo se incrementó con la estabilidad de la moneda, cuando el crédito se convirtió en uno de los mecanismos para administrar el presupuesto familiar. Asimismo, un entorno económico más estable cambió el enfoque de las instituciones financieras, que comenzaron a promover las operaciones de crédito no solo a través de la banca tradicional, sino también a través de entidades microfinancieras como cajas municipales, Edpymes, financieras y banca especializada.

El crédito ha demostrado ser un importante dinamizador de la actividad económica, al impulsar la demanda interna al aumentar el consumo de los hogares y la productividad de las microempresas y pequeñas empresas. Sin embargo, la oferta crediticia disponible en el mercado para la adquisición de bienes son abundantes, aunque no necesariamente ventajosas para quienes pretenden utilizarlas. Por lo tanto, el crédito está asociado con el desarrollo económico, ya que proporciona acceso para las poblaciones en situación de vulnerabilidad económica y, por lo tanto, es un factor de inclusión social.

Es innegable que el crédito permite resolver el problema del acceso a financiamiento de muchas familias para adquirir bienes e incluso son indispensables para su bienestar. No existe duda respecto a la importancia del crédito para generar crecimiento, puesto que, al proporcionar un mayor consumo, se permite a las empresas producir a una escala más grande y contratar más trabajadores, lo cual aumenta el poder adquisitivo de la población, con una mejora en su nivel de vida.

Sin embargo, es importante señalar que, además de incluir financieramente a las familias, el crédito también puede llevarlos a la exclusión social, dependiendo del modo en que se administren las facilidades crediticias obtenidas y las condiciones crediticias.

La sociedad moderna depende del crédito, debido a que, en situación de vulnerabilidad económica, es esencial para la subsistencia del individuo. Lo que actualmente se observa es el inmediatismo por consumir cada vez más, y la negligencia de las instituciones financieras al otorgar el crédito, sin evaluar con cautela y responsabilidad la capacidad crediticia del individuo. 


\section{Sobreendeudamiento como producto de una sociedad del consumo}

El crédito es un mecanismo que estimula el consumo. Sin embargo, en el contexto de la sociedad de consumo se genera una distorsión de la función social del crédito (Goldenberg Serrano, 2017). En el Perú hay dos tipos de consumidores, los privilegiados y los desfavorecidos.

En el primer grupo el acceso de esta población al crédito es más fácil; además, goza de mejores condiciones. En cambio, los consumidores desfavorecidos, cuyo acceso a bienes y servicios de cualquier tipo depende del crédito, son objeto constante del consumo de productos y servicios no esenciales.

No se trata de victimizar al deudor, ni de condenar el crédito o la publicidad, sino de visibilizar la falta de un sistema de protección efectivo para el consumidor financiero. La situación lo amerita: en caso de sobreendeudamiento, la insolvencia es la consecuencia inicial de esta situación, lo que implica, posteriormente, ejecutar los activos del deudor o de sus avales, para satisfacer las deudas contraídas y vulnerar por completo su integridad humana.

La prevalencia del interés económico por encima del interés de los consumidores se evidencia de manera constante en el sistema financiero. De acuerdo con el Instituto Nacional de Defensa de la Competencia y de la Protección de la Propiedad Intelectual (Indecopi, 2019), el número de reclamos llegó a 2458 258, con un incremento del 18\% respecto a 2018.

El otorgamiento de crédito sin considerar la real capacidad crediticia del solicitante puede tener como consecuencia la quiebra del consumidor. Cabe señalar que el crédito en sí no es malo para la sociedad, dado el papel prominente que tiene en la economía.

Vale la pena mencionar que la doctrina ha sido muy crítica de los métodos, a menudo abusivos, utilizados por la publicidad en su papel de atraer al consumidor. Tal comportamiento se identifica fácilmente a través de las omisiones en los anuncios que se difunden en los principales medios, especialmente dirigida a los consumidores más vulnerables. Al respecto, Vinyals y García (2014) evidencian, respecto a la publicidad de los créditos, la omisión de información necesaria para que el consumidor realice un correcto juicio respecto al lado positivo y negativo de los productos financieros. Los autores concluyen que la omisión de detalles en la publicidad bancaria se realiza de manera voluntaria y consciente porque favorece los intereses de los anunciantes en detrimento de sus clientes y potenciales consumidores. 
Las instituciones financieras cuentan con áreas de mercadeo que planifican sus estrategias de marketing y posicionamiento, las cuales difunden a través de los medios de comunicación. Posteriormente, tras la difusión de la publicidad, el mensaje comienza a actuar en los consumidores, pues produce un cambio conceptual respecto al significado del crédito; su poder, más allá de la adquisición de bienes o servicios, confiere estatus.

La agresividad de la publicidad también está dirigida a poblaciones vulnerables, con el objetivo de atraer a más consumidores de productos crediticios, incluso dándoles una impresión sesgada que usar crédito puede transformarlos en emprendedores de éxito. Este enfoque termina impactando drásticamente en el sector financiero, en vista de los efectos adversos que la utilización irresponsable del crédito puede llevar a la vida de quienes no cuentan con la suficiente educación financiera o no cuentan con toda la información necesaria respecto a las condiciones crediticias.

Los consumidores más vulnerables no están en condiciones de ejercer la autonomía de su voluntad. Esto se debe a que los consumidores no conocen sus derechos como consumidores y firman impulsivamente los contratos, sin conocer las condiciones crediticias del producto financiero que contrataron.

Desde ese modo, el efecto de la publicidad en el segmento microempresa funciona como un mecanismo para promover el sobreendeudamiento, debido a la omisión de las condiciones de los productos publicitados, y no menciona las consecuencias que puede causar el sobreendeudamiento.

El crédito es un mecanismo para la inclusión social. La carencia de crédito impide a las personas contar con oportunidades que les permitan lograr su desarrollo. Por ese motivo la publicidad está diseñada para transmitir la idea inmediata de que el crédito promueve su progreso, y también crea expectativas respecto a la facilidad y rapidez para obtener el crédito.

Las campañas de publicidad no solo se difunden en la televisión, sino también en la radio, YouTube y redes sociales. Como si lo antes señalado fuera insuficiente, las tarjetas de crédito se promocionan agresivamente a través de centros de llamadas, pese a que, de acuerdo con el artículo 58.1.e del Código de Protección y Defensa del Consumidor, están prohibidos los mensajes de texto, llamadas y correos electrónicos de promoción.

Evidentemente, es poco probable que la publicidad conduzca a los consumidores a una racionalidad efectiva de elección, basada en información precisa y correcta sobre la esencia del producto o servicio. Además, las campañas publicitarias recientes apelan a las emociones o al sentido 
de pertenencia al segmento emprendedor, no se refieren a un producto en particular, lo cual las exime de mostrar información respecto a tasas de interés, condiciones crediticias o que el otorgamiento de créditos está sujeto a evaluación. Por lo tanto, se hace difícil realizar una efectiva protección a los consumidores mediante campañas publicitarias que podrían hacerles incurrir en sobreendeudamiento que supere su capacidad de pago.

Debido a la alta competencia entre instituciones microfinancieras, los procedimientos de otorgamiento crediticio se han flexibilizado. Lo mismo ocurre al momento de evaluar la capacidad de pago del solicitante. Aunque la situación puede considerarse como positiva, la forma en que las instituciones financieras otorgan los créditos pone en serio riesgo las economías familiares de los consumidores.

En ausencia de regulación específica respecto a prestatarios sobreendeudados, debe tenerse en cuenta que el Código de Protección y Defensa del Consumidor, Ley 29571, busca reducir las disparidades entre las partes involucradas en el contrato de crédito. Por ese motivo, el artículo 96 de la referida norma señala que la entidad financiera debe proporcionar al consumidor la información necesaria, clara y precisa en la hoja resumen, con todas las condiciones del crédito, previo a su otorgamiento. Esta disposición establece qué entidad financiera debe informar respecto al costo real del crédito que se otorgará y todos sus elementos, tales como tasas de interés compensatorias y moratorias, plazo, entre otros que se estipulan en el contrato.

Es evidente que el contrato de adhesión que firma el prestatario establece una relación continua, de larga duración, e involucra cálculos y tasas que a menudo son incomprensibles para el consumidor. Al respecto, Goldenberg (2020) señala que el modelo basado en el deber de proporcionar información y la promoción de la educación financiera, para lograr que el cliente financiero sea diligente con sus deudas, ha fallado en Chile, al no tenerse en cuenta las características cognitivas y conductuales del consumidor financiero. Esto se debió a que las instituciones financieras ignoraron la estructura bilateral proveedor-consumidor en el otorgamiento de crédito, al basar sus expectativas solo en la diligencia de los consumidores.

Por eso, es necesario que la entidad financiera informe al consumidor no solo respecto a las condiciones del producto financiero, sino también de aquellas situaciones desfavorables para el prestatario, como medio de prevención. Se debe tener en cuenta la protección de la información, la transparencia y la responsabilidad en el otorgamiento del crédito, el cual tiene como objetivo equilibrar la relación entre la entidad financiera y el consumidor. 


\section{La dignidad humana de los sobreendeudados}

Cuando el deudor, debido a diversas situaciones, no puede pagar sus deudas y ve afectado su historial crediticio, tiene consigo consecuencias de gran impacto en la vida de los consumidores, especialmente porque afecta su dignidad humana, lo que provoca su exclusión del mercado laboral.

Además de la deuda acumulada y la calificación crediticia desfavorable, el consumidor sobreendeudado debe soportar el estigma del sistema financiero, causado por la inserción de su nombre en centrales de riesgo, donde será considerado un mal pagador. Significa decir que, a partir de ese momento, cualquier actividad que requiera de una evaluación crediticia será denegada a ese consumidor.

Muchos de estos consumidores dependen del crédito para su propia subsistencia y la de sus familias, por lo que el daño causado como resultado del impago es inmensamente superior a los índices de morosidad que representan.

La dignidad del ser humano merece el mismo respeto y consideración por parte del Estado y la comunidad, lo que implica una serie de derechos y deberes fundamentales que aseguren a la persona su defensa ante actos degradantes, ya que vienen a garantizar las condiciones existenciales mínimas para una vida digna, además de proporcionar y respetar su decisión respecto a temas de su propia existencia en comunión la vida de los otros seres humanos.

La imposibilidad de pagar sus deudas y la afectación en sus gastos diarios hacen que el cliente financiero sobreendeudado pierda su capacidad de consumo y, en consecuencia, se afecte su dignidad y la de su familia.

Cuando las dificultades de pagar las obligaciones financieras están precedidas de la pérdida del trabajo y dificultades personales, el cliente puede ver afectada su autoestima. La incapacidad del cliente sobreendeudado para controlar sus ingresos y gastos no solo se trata de un asunto de índole financiera. Las consecuencias del sobreendeudamiento en los hogares, especialmente cuando están asociadas con el desempleo o una crisis económica generalizada, afectan las relaciones sociales de los prestatarios sobreendeudados $y$, además, ven afectada también su propia imagen.

De esta manera, el fenómeno abarca mucho más que una cuestión económica, ya que afecta directamente la dignidad de la persona humana, por lo que debe ser tratado como un problema social y legal.

Vale la pena destacar la importancia de la dignidad del consumidor frente al problema del sobreendeudamiento, considerando el problema 
en relación con las necesidades internas del individuo, así como las consecuencias externas que se causan.

La protección legal adecuada debe estar enmarcada, entonces, con el fin de garantizar las condiciones mínimas existenciales para una vida digna, lo que incluye la restricción de cualquier acto de naturaleza degradante aplicada a los consumidores, sobre todo como una forma de protección de la dignidad de la persona humana. La contratación de personal no debería estar supeditada al historial crediticio de una persona. En ese sentido, Lescano Ancieta (2016) planteó el Proyecto de Ley 1463/2016, a fin de establecer sanciones para las personas naturales o jurídicas que establezcan la conducta crediticia como requisito tácito o implícito para acceder a un trabajo, debido a que se trata de actos discriminatorios que atentan contra los derechos de la persona y su condición económica.

\section{Consecuencias sociales y legales del sobreendeudamiento}

La oferta de crédito dinamiza diversos sectores económicos, lo cual propicia el crecimiento y el desarrollo del mercado. Sin embargo, a pesar de todos los beneficios que conlleva el crédito, no se pueden negar las consecuencias nocivas que pueden traer al consumidor financiero en casos como el sobreendeudamiento y el impago de sus obligaciones financieras.

De este modo, un producto de inclusión financiera, el crédito, se convierte en la puerta de la exclusión, por el sobreendeudamiento de los consumidores y encontrarse en centrales de riesgo por falta de pago de sus deudas. De hecho, el sobreendeudamiento genera varias situaciones que son extremadamente desagradables para el consumidor, como la cobranza abusiva, la discriminación laboral y el menoscabo de su calidad de vida.

De una forma u otra, el sobreendeudamiento genera situaciones nocivas. Es, en efecto, una fuente de tensión dentro de la familia que a menudo conduce al divorcio, lo que agrava la situación de sobreendeudamiento. Puede llevar a las personas sobreendeudadas a reducir sus gastos básicos o descuidar la educación de sus hijos. De ese modo, se configura la exclusión social. El sobreendeudamiento es una fuente de aislamiento, de marginación, de estigma social del individuo. Cuando este fenómeno se produce con mayor frecuencia, más aumenta su costo social y, en consecuencia, nace la necesidad de combatirlo.

Por lo tanto, el sobreendeudamiento es un problema social, caracterizado por la exclusión financiera de las personas y la privación de una existencia digna. Desde esa perspectiva, una oferta masiva de crédito, sin una medida legislativa para monitorear y prevenir problemas derivados 
de esta práctica, puede generar una profunda crisis de confianza en el país, especialmente de los sectores económicos menos favorecidos.

En vista de este problema y debido a las consecuencias sociales que conlleva, la intervención del Estado es imprescindible a través de una reforma en el Código de Protección y Defensa del Consumidor.

El derecho a la información es el mayor instrumento preventivo para evitar un daño al consumidor financiero, quien debe ser consciente de los riesgos involucrados al obtener un producto crediticio, principalmente debido a la falta de conocimiento respecto a las condiciones del crédito y las consecuencias del impago. El consumidor debe tener información previa y adecuada de todos los aspectos contractuales sobre el crédito que pretende obtener, sobre todo en relación con las penalidades y consecuencias negativas que acarrea un incumplimiento en el contrato.

\section{Sobreendeudamiento en el derecho comparado}

En muchos países, el sujeto recibe un trato diferente al otorgado en la legislación peruana, respecto a la protección del consumidor en situación de sobreendeudamiento. En países como Francia, Alemania, Países Bajos, Estados Unidos y el Reino Unido se reconoce la quiebra civil o procedimientos similares, que conducen a la desaparición de la totalidad o parte de la deuda del individuo después de la liquidación de sus activos, con participación judicial o un acuerdo supervisado por el juez para reprogramar la deuda, reducir el monto adeudado, disminuir los intereses, etc.

\section{Francia}

En Francia, la Ley 89/1010 de 1989, más conocida como Ley Neiertz, tuvo como objetivo controlar los riesgos de endeudamiento excesivo en relación con el tamaño de los créditos personales, cada vez más presente en la sociedad francesa. A la fecha se tiene el procedimiento de recuperación personal (procedure de traitement du surendettement), el cual permite eliminar las deudas de un individuo sobreendeudado cuya situación financiera está tan deteriorada que no es posible ninguna acción de tratamiento, ya sea través de un plan de recuperación o por medidas impuestas. Para ello, se requiere que la persona tenga buena fe. Este proceso se lleva a cabo por iniciativa de la comisión de sobreendeudamiento con el consentimiento de la persona sobreendeudada. Si la persona sobreendeudada no tiene propiedades, no habrá liquidación judicial, es decir, sin una venta de sus bienes (San Luis, 2015).

Observando el sistema legal francés, es posible resaltar la solidaridad social, que es perceptible mediante la adopción de procedimientos humanitarios en el tratamiento de los sobreendeudados, incluso 
estableciendo un periodo para la reflexión del consumidor al concluir un acuerdo de crédito, con el objetivo para garantizar la libre elección y la necesidad real de su realización.

Según San Luis (2015), el legislador francés tuvo en cuenta la posición subjetiva del deudor a fin de determinar si el deudor es de buena fe o no, 0 si se encuentra en un estado de sobreendeudamiento irremediablemente comprometido. Si el deudor es de buena fe, puede, mediante un contrato o arreglo concertado con sus acreedores, beneficiarse de la «reprogramación». Incluso si la condición del deudor es tan grave que el acuerdo no se puede concluir o la condición se vuelve imposible hasta que se decida, el procedimiento de sobreendeudamiento del deudor puede guiarse hacia la «recuperación personal», independientemente si el deudor tiene o no activos distintos a los requeridos para su existencia, o estén sujetos o no a liquidación judicial.

En Francia se establece un trato con los acreedores para que el deudor tenga la posibilidad de beneficiarse de un aplazamiento de sus deudas. Si un deudor no puede asumir sus deudas, se podría iniciar un procedimiento de rehabilitación personal en el sentido de que no es posible crear un plan de pago, lo que puede denominarse proceso de liquidación legal si el deudor tiene activos suficientes para eximirse del uso no financiero distinto de los necesarios para su existencia o para el desarrollo de su vida profesional (Bozzo Hauri, 2020).

\section{Alemania}

La Verbraucherkreditgesetz, más conocida como Ley de Crédito al Consumo, está en vigencia desde 1991 y regula todas las relaciones de crédito de consumo existentes en el mercado. Su objetivo principal es la protección social del consumidor, que va desde la reducción de los intereses moratorios hasta las reprogramaciones de pago.

En el derecho alemán la declaración de quiebra se realiza a petición del deudor o de los acreedores, y su justificación suele ser que la deuda está impaga y existe sobreendeudamiento. Esto está previsto por la orden de insolvencia sobre la terminación de los pagos cuando el deudor no está en condiciones de satisfacer sus obligaciones de pago y cuando sus pagos se han suspendido. La confirmación de la insolvencia es obligatoria en Alemania como condición previa para la solicitud de quiebra, incluso cuando el mismo deudor lo solicite. Así es como el estatuto de insolvencia alemán presupone la insolvencia como condición del procedimiento concursal incluso para los deudores (Campos, 2018).

El objetivo del código de insolvencia Insolvenzordnung (InsO) de enero de 1999, modificado en diciembre de 2001, es desarrollar un marco 
regulatorio que conduzca a una gestión de la insolvencia bajo los principios de prioridad de intereses y reorganización de deudores. Si el deudor es una persona física, podrá ser liberado de sus deudas en virtud de un proceso especial de insolvencia del consumidor (Braun, 2004).

El proceso de insolvencia de la persona natural y la posterior exoneración de la deuda están condicionados a un plazo de buena conducta, tras lo cual el Tribunal competente determinará la cancelación de la deuda ante todos los acreedores. La palabra sobreendeudamiento no se utiliza en la legislación alemana para referirse a la insolvencia del consumidor, sino solo en aquellas situaciones en las que sus activos no son suficientes para satisfacer sus obligaciones. Sin embargo, el código de insolvencia alemán permite la posibilidad de exonerar a los deudores honestos para restringir el principio de responsabilidad patrimonial (Rey del Río, 2016).

\section{Estados Unidos}

En el sistema norteamericano existe una amplia disponibilidad para la insolvencia civil, ya que el régimen es muy liberal y, por disposición constitucional, la insolvencia es un asunto de derecho y jurisprudencia federal.

Por lo tanto, en Estados Unidos se desarrolló un «esquema de quiebra de clientes», con el objetivo de hacer frente a las situaciones de sobreendeudamiento del consumidor a través del Título 11 del Código de Estados Unidos para mitigar los efectos adversos de situaciones en las que las personas enfrentan problemas financieros. Cualquier persona física que viva, tenga su hogar, establecimiento comercial o propiedad en Estados Unidos puede declararse en quiebra. Si una persona física ha presentado una solicitud, se necesita una certificación de que se ha obtenido una sesión individual o grupal dentro de los 180 días antes de la solicitud de quiebra, para obtener asesoramiento sobre las diversas formas de lidiar con una quiebra. Para iniciar el procedimiento, la solicitud concursal del deudor debe presentarse ante un tribunal de quiebras, seguida de una declaración que acredite todas las propiedades, derechos y obligaciones vigentes. Este documento debe estar redactado de manera veraz, pues de lo contrario se incurrirá en responsabilidad civil e incluso penal (Rey del Río, 2016).

El modelo de «debt discharge» estadounidense, obedece a un modelo histórico del estatuto estadounidense que data de 1868, a través de la Bankruptcy Act. El concepto detrás de este modelo es dar a los deudores insolventes una «segunda oportunidad» para devolverlos al mercado crediticio a través del esquema de liquidación conocido en Estados Unidos. El capítulo 7 exige que el deudor esté legítimamente liberado de la obligación para tener un «nuevo comienzo» (Aparicio, 2018). 
De hecho, un modelo de dos de los más utilizados en Estados Unidos en relación con sus leyes de quiebras, según el código de Estados Unidos (capítulo 13), es el llamado plan de pago, según el cual el deudor asigna todas sus ganancias para saldar sus obligaciones luego de concluirse el plan. Sin embargo, el capítulo 7 muestra que, desde su reforma desde 2005 , ha sido el más usado y eficaz. Este modelo consiste en enumerar resumidamente la deuda y los activos, y paraliza toda acción ejecutiva para aquel deudor que solicita la declaración concursal. El deudor será liberado de sus obligaciones después de que haya sido desposeído de sus bienes y distribuido a los acreedores para reiniciar sus actividades (Aparicio, 2018).

\section{Propuesta de enmienda al Código de Protección y Defensa del Consumidor}

El complejo fenómeno del sobreendeudamiento requiere la participación activa del Estado a través de un dispositivo legal que garantice el equilibrio de las relaciones contractuales en los productos financieros.

La medida sugerida de prevención consiste en proporcionar al consumidor toda la información necesaria sobre el contrato que tiene la intención de firmar, para que pueda evaluar los costos y riesgos que implica de la operación crediticia, y, por otro lado, el proveedor de crédito, que deberá evaluar la posibilidad de incumplimiento por parte del prestatario y minimice su riesgo crediticio.

También consiste en evitar la firma de contratos que son manifiestamente desproporcionados. Lo que se pretende aquí es evitar que ocurran, es decir, que se tomen medidas antes de la celebración del contrato, con información en la Hoja Informativa Resumen, no solo los costos del crédito, tal como se establece en el artículo 93 del Código de Protección y Defensa del Consumidor, sino también las eventuales consecuencias de un incumplimiento que permitan evaluar al consumidor financiero si es adecuado obtener el préstamo.

Asimismo, una medida preventiva adicional es la regulación de la publicidad de entidades financieras, de modo que la publicidad únicamente puede ser difundida con un mensaje que advierta sobre los posibles riesgos y consecuencias del sobreendeudamiento. Lo antes indicado como medida adicional a lo estipulado respecto a la publicidad crediticia se basa en el artículo 83 del Código de Protección y Defensa del Consumidor, el cual estipula que se debe consignar en los anuncios la tasa de costo efectivo anual (TCEA).

Respecto a la publicidad de créditos, Vinyals y García (2014) señalan que la publicidad de servicios financieros no centra el mensaje 
publicitario en los aspectos económicos de los anuncios y se restringe a vender beneficios como la inmediatez para recibir el crédito o la facilidad de la obtención, de modo que omite o deja aspectos esenciales y relevantes a un segundo nivel, con la finalidad de que el consumidor no tome una decisión racional. En el Perú las prácticas antes mencionadas son comunes en la publicidad de las instituciones financieras, que a menudo difunden sus anuncios con el claro objetivo de transmitir la idea de la rapidez y facilidad en el otorgamiento de crédito.

Los consumidores financieros son susceptibles a los nuevos métodos de marketing y los términos utilizados en sus anuncios. El neuromarketing permite comprender las necesidades del cliente y medir su reacción a los estímulos de la publicidad y el contacto con asesores financieros en la obtención de productos financieros. La oferta de préstamo no es transparente, sencilla ni veraz, lo cual puede conducir al consumidor al sobreendeudamiento. Por tanto, es necesario contar con medidas preventivas, mediante mecanismos que aporten soluciones a este problema (Alcántara-Francia, 2019).

Es notable la falta de regulación en el sector en el otorgamiento crediticio. Sin embargo, los países más desarrollados cuentan con normas que regulan el tema, mientras que en el Perú solo existe el Código de Protección al Consumidor, que aún es incipiente en el tratamiento de este asunto. Ante esta situación, se requiere la acción del Estado a través de un mecanismo legal para proteger a los consumidores sobreendeudados.

La preocupación contemporánea con el consumidor sobreendeudado tiene su origen en la Ley 89-1010 del 31 diciembre de 1989, más conocida como la Ley Neiertz (Granell, 2020). Posteriormente, la regulación en diversos países para proteger a los consumidores sobreendeudados ha evolucionado significativamente en el tiempo.

El tratamiento del sobreendeudamiento es una verdadera prioridad legislativa, considerando los efectos económicos y sociales negativos de condenar a una persona insolvente a su exclusión social. Debido a la imprudencia del sistema financiero en la colocación de créditos, las pérdidas del sector financiero corrieron a cargo del Estado, que tuvo que gastar mucho más dinero en solucionar situaciones de exclusión social a las que los deudores se vieron expuestos al no poder saldar sus deudas. Condenar al deudor a la exclusión social desincentiva el consumo y la inversión tras la liquidación de su patrimonio. El efecto sobre el desempleo también es negativo (Cuena Casas, 2014). 


\section{Conclusiones}

En vista de todo el contenido presentado, se puede ver que el crédito es la fuerza impulsora de la economía, como mecanismo que constituye un estímulo para el consumo.

Sin embargo, en las sociedades de consumo se origina una distorsión de la función social del crédito. Además de proporcionar inclusión social a las familias, el crédito también puede conducir a la exclusión social, dependiendo del mecanismo y la proporción de su otorgamiento, dado que muchas personas terminan contrayendo deudas superiores a su capacidad de pago.

Los factores que conducen al sobreendeudamiento están asociados con el comportamiento del consumidor $y$, principalmente, las acciones de las instituciones financieras, a través de publicidad y otorgamiento de créditos sin las debidas medidas de mitigación de riesgos para otorgarlos. Por lo tanto, el presente artículo tiene por objetivo prevenir el sobreendeudamiento de buena fe de los consumidores.

Con el fin de permitir el tratamiento y la prevención del sobreendeudamiento, se han señalado soluciones adoptadas en el derecho comparado, donde existen medios legales eficaces para proteger al consumidor financiero.

Se propone una reforma del Código del Consumidor con finalidad preventiva, para que el consumidor cuente con información adecuada y suficiente de las condiciones crediticias y también de las consecuencias que puede acarrear el sobreendeudamiento previo a la firma de los contratos de crédito, con el objetivo de hacer que su elección sea libre e informada.

Como se menciona en el presente artículo, la exclusión social es mayor en aquellos países cuyo sistema legal aún no presenta un tratamiento especial para el sobreendeudamiento, como es el caso peruano. En vista de esto, no se puede soslayar sus consecuencias sociales negativas. Asimismo, debe tenerse en cuenta que las reformas propuestas tienen como objetivo proteger tanto al consumidor como al ahorrista.

\section{Contribución de autoría}

Fernando Ramos Zaga ha participado en la elaboración, la compilación de datos, la redacción y el consentimiento de la versión final del presente artículo.

\section{Fuente de financiamiento}

Autofinanciado.

\section{Potenciales conflictos de interés}

El autor declara no tener conflictos de interés. 


\section{REFERENCIAS BIBLIOGRÁFICAS}

Alcántara-Francia, O. A. (2019). Neuromarketing y sobreendeudamiento: ¿Matrimonio feliz? Recuperado de https://core.ac.uk/download/ pdf/286065461.pdf

Aparicio, C. C. M. (2018). Derecho comparado de sobreendeudamiento de la persona física: Argentina, Portugal, México, USA. Revista Lex Mercatoria. Doctrina, Praxis, Jurisprudencia y Legislación, pp. 95-122. Recuperado de https://revistas.innovacionumh.es/index.php/lexmercatoria/article/ download/557/908

Astorne Guillén, M. J., Aquije Milanta, J. C. y Paredes Núñez Melgar, S. P. (2017). Reglamentación y estrategia institucional para evitar el sobreendeudamiento en el sector de créditos minorista de consumorevolvente en Lima Metropolitana. 2015-2016. Recuperado de http:// repositorio.ucss.edu.pe/bitstream/handle/UCSS/516/Astorne_Aquije_ Paredes_tesis_maestria_2017.pdf?sequence $=1$

Bozzo Hauri, S. (2020). Sobreendeudamiento del consumidor en Chile: una revisión a la luz del derecho europeo. Revista de Derecho (Valdivia), 33(1), pp. 159-183. Recuperado de https://scielo.conicyt.cl/scielo. php?pid=S0718-09502020000100159\&script=sci_arttext

Braun, S. (2004). Panorama del Derecho Concursal alemán y europeo. Revista Icade. Revista de las Facultades de Derecho y Ciencias Económicas y Empresariales, 61, pp. 313-332. Recuperado de https://razonyfe.org/index. php/revistaicade/article/download/6432/6243

Caballero Germain, G. (2018). Sobreendeudamiento y exoneración legal de los saldos insolutos en el procedimiento concursal del consumidor. lus et Praxis, 24(3), pp. 133-172. Recuperado de https://scielo.conicyt.cl/scielo. php?pid=S0718-00122018000300133\&script=sci_arttext\&tlng=en

Cuena Casas, M. (2014). El sobreendeudamiento privado como causa de la crisis financiera y su necesario enfoque multidisciplinar. Recuperado de https://eprints.ucm.es/28066/1/El\%20sobreendeudamiento\%20privado $\% 20$ como $\% 20$ causa $\% 20$ de $\% 20$ la $\% 20$ crisis $\% 20$ financiera $\% 20$ y $\% 20$ su\%20necesario\%20enfoque\%20multidisciplinar.pdf

De la Maza Gazmuri, I. (2007). ¿Llegar y llevar?: una mirada al crédito de las casas comerciales. Revista de Derecho (Valdivia), 20(1), pp. 61-84. Recuperado de https://scielo.conicyt.cl/scielo.php?pid=S071809502007000100003\&script $=$ sci_arttext\&tlng $=p$

Esteban, V., Zegarra, E. y Acosta, M. (2018). Factores del sobreendeudamiento en los servidores administrativos de la Universidad Pública en la ciudad de Tingo María. RevIA, 5(1-2). Recuperado de http://revistas.unas. edu.pe/index.php/revia/article/viewFile/56/43 
Gallardo Mantilla, M. L. y Minchan Huamán, E. Y. (2017). Nivel de conocimiento de las condiciones de crédito que tienen los clientes de las tiendas comerciales de electrodomésticos Efe y Curacao en la ciudad de Cajamarca en el año 2016. Recuperado de http://repositorio.upagu.edu.pe/bitstream/handle/UPAGU/298/TESIS.pdf?sequence

Goldenberg Serrano, J. L. (2017). El necesario ajuste de la asignación del riesgo de sobreendeudamiento en la regulación de las tarjetas de crédito: desde un sistema basado en los deberes de información a un modelo de corresponsabilidad. Revista de Derecho (Valparaíso), 49, pp. 55-98. Recuperado de https://scielo.conicyt.cl/scielo.php?pid=S0718$68512017000200055 \&$ script $=$ sci_arttext\&tlng=n

Goldenberg Serrano, J. L. (2020). El sobreendeudamiento y los paradigmas del consumidor financiero responsable y del proveedor financiero profesional. lus et Praxis, 26(1), pp. 1-27. Recuperado de https://scielo.conicyt.cl/ scielo.php?pid=S0718-00122020000100001\&script=sci_arttext\&tlng=e

González, A. y González-Vega, C. (2003). Sobreendeudamiento en las microfinanzas bolivianas, 1997-2001. Recuperado de https://www.researchgate.net/profile/Adrian_Gonzalez5/publication/228200296_Overindebtedness_in_the_Bolivian_Microfinance_Sector_1997-2001_Sobreendeudamiento_en_Las_Microfinanzas_Bolivianas_1997-2001/ links/5a6b4bde0f7e9b1c12d402fb/Overindebtedness-in-the-BolivianMicrofinance-Sector-1997-2001-Sobreendeudamiento-en-Las-Microfinanzas-Bolivianas-1997-2001.pdf

Granell, V. B. (2020). Sobreendeudamiento y protección de los consumidores (Universidad de Almería). Recuperado de https://www.editorialreus. es/static/pdf/primeraspaginas_9788429023091_sobreendeudamiento-yproteccion-de-consumidores.pdf

Herrera Pachari, J. L. (2015). Análisis jurídico de las cláusulas abusivas en los contratos de consumo. Recuperado de http://repositorio.unsa.edu.pe/ bitstream/handle/UNSA/2210/DEhepajl.pdf?sequence=1\&isAllowed=y

Holguín Chambilla, L. M. (2018). Factores que influyen en el sobreendeudamiento de los clientes de una Entidad Microfinanciera de Arequipa, 2017. Recuperado de http://bibliotecas.unsa.edu.pe/bitstream/handle/ UNSA/7967/EChochlm.pdf?sequence $=1$ \&isAllowed $=\mathrm{y}$

Instituto Nacional de Defensa de la Competencia y de la Protección de la Propiedad Intelectual (2019). Informe Anual sobre el Estado de la Protección de los Consumidores en el Perú, 2019. Recuperado de https://repositorio.indecopi.gob.pe/handle/11724/7794 
Japaze, M. B. (2015). Sobreendeudamiento del consumidor. Remedios preventivos y de saneamiento. Ámbitos y procedimientos de actuación. Recuperado de https://gredos.usal.es/bitstream/handle/10366/128453/ DDP_JapazeMB_Sobreendeudamientoconsumidor.pdf;jsessionid=F8630 44B2D113C839F5C325EC4B445A9?sequence $=1$

Lescano Ancieta, Y. (2016). Proyecto de ley que modifica el artículo 3 de la ley 26772, modificada por la ley 27270, que dispone que las ofertas de empleo y acceso a medios de formación educativa no podrán contener requisitos queconstituyan discriminación, anulación o alteración de igualdad de oportunidades o de trato. Recuperado de https://leyes.congreso.gob. pe/Documentos/2016_2021/Proyectos_de_Ley_y_de_Resoluciones_Legislativas/PL0147320170607..pdf

Neme Villarreal, M. L. (2009). Buena fe subjetiva y buena fe objetiva; equívocos a los que conduce la falta de claridad en la distinción de tales conceptos. Revista Derecho Privado, 17(45). Recuperado de https://www.redalyc.org/pdf/4175/417537591002.pdf

Rengifo Vásquez, O. U. y Ampuero Ovalle, M. A. S. (2018). La oferta crediticia de las instituciones financieras y el sobreendeudamiento de las micro y pequeñas empresas en la zona del mercado municipal de Yarinacocha en el departamento de Ucayali 2010-2016. Recuperado de http://repositorio. unu.edu.pe/bitstream/handle/UNU/4391/UNU_ECONOMIA_2020_TESIS_ OSCAR-RENGIFO_MERY-AMPUERO.pdf?sequence=1

Rey del Río, D. (2016). Análisis del sobreendeudamiento del consumidor y la segunda oportunidad en le derecho español y comparado. Recuperado de https://uvadoc.uva.es/bitstream/handle/10324/21802/TFG-E-282. pdf? sequence $=1$ \&isAllowed $=y$

Rodríguez, M. L. (2016). Cláusulas abusivas en el otorgamiento de créditos: Tarjeta de crédito (disertación de doctorado). Recuperado de https://repositorio.uesiglo21.edu.ar/bitstream/handle/ues21/11922/ Rodriguez,\%20Marcela\%20Liliana.pdf?sequence $=1$

San Luis, R. L. (2015). El tratamiento del sobreendeudamiento de los particulares en Francia. Revista de Derecho Civil, 2(2), pp. 207-228. Recuperado de https://nreg.es/ojs/index.php/RDC/article/download/128/104

Vásquez Vílchez, L. L. (2017). Factores del sobreendeudamiento que afectan la economía familiar de la Urbanización los Claveles del Distrito Veintiséis de Octubre, Piura 2017. Recuperado de http://repositorio.ucv.edu.pe/bitstream/handle/20.500.12692/10788/vasquez_ vl.pdf?sequence $=1$ \&isAllowed $=y$

Villanueva, A. E. V. (2010). Cláusulas abusivas en los contratos de tarjeta de crédito. Revista de Derecho, 13, pp. 63-98. Recuperado de https:// scielo.conicyt.cl/scielo.php?pid=S0718-09502007000100003\&script=sci_ arttext\&tlng=p 
Vinyals, M. y García, Á. (2014). Análisis ético de la publicidad de los créditos al instante en España. Recuperado de http://udem.scimago.es/index.php/ anagramas/article/download/437/395

Recepción: 20/10/2020

Aceptación: 27/1/2021 